Supporting Information For:

\title{
Production and Release of Selenomethionine and Related Organic Selenium Species by Microorganisms in Natural and Industrial Waters
}

\author{
Kelly L. LeBlanc*,†, Dirk Wallschläger ${ }^{\ddagger}$ \\ ${ }^{\dagger}$ Environmental and Life Sciences Graduate Program, ${ }^{\ddagger}$ Water Quality Centre, Environmental \\ and Resource Science Program, and Department of Chemistry, Trent University, 1600 West \\ Bank Drive, Peterborough, Ontario, Canada K9J 7B8 \\ * direct correspondence to: kellyleblanc@trentu.ca
}

\section{Contents}

S-2 Table S-1: Concentrations of inorganic Se species in algal culture media and Porcupine River water, related organic Se species are outlined in Table 1

S-3 Figure S-1: Rough schematic of the biological formation of the observed organic Se metabolites produced by algae and bacteria exposed to inorganic selenium, as selenate. Pink: starting species, green: metabolites with identity confirmed by ES-MS/MS, blue: metabolites identified by coelution in AEC-ICP-DRC-MS. Dotted arrows: transformations that have been observed in the literature (details in text).

S-4 Figure S-2: AEC-ES-MS/MS chromatogram of the medium of a culture of Chlorella kesslerii grown in the presence of $25 \mathrm{ppb} \mathrm{Se}(\mathrm{VI})$. The product of four isotopic transitions $\left({ }^{77} \mathrm{Se},{ }^{78} \mathrm{Se},{ }^{80} \mathrm{Se}\right.$, and $\left.{ }^{82} \mathrm{Se}\right)$ for the fragmentation $\mathrm{SeOMet}>\mathrm{SeCH}_{3} \mathrm{O}^{-}$is shown. Overlaid is the ${ }^{80} \mathrm{Se}$ signal for the AEC-ICP-DRC-MS analysis of a (freshly prepared) SeOMet standard to demonstrate coelution.

References for Supporting Information 
Table S-1: Concentrations of inorganic Se species in algal culture media and Porcupine River water, related organic Se species are outlined in Table 1

\begin{tabular}{|c|c|c|c|c|}
\hline & Se(IV) & Se(IV) & SeCN $^{-}$ & $\begin{array}{c}\text { Total Se } \\
\text { (Sum of } \\
\text { Species) } \\
\text { left in solution } \\
(\mathbf{p p b})\end{array}$ \\
\hline $\begin{array}{c}\text { C. vulgaris } \\
+10 \text { ppb Se(VI) }\end{array}$ & 1.19 & 4.15 & 0.588 & $(6.29)$ \\
\hline $\begin{array}{c}\text { C. kesslerii } \\
+10 \text { ppb Se(VI) }\end{array}$ & 1.08 & 5.86 & 1.33 & $(8.97)$ \\
\hline $\begin{array}{c}\text { S. obliquus } \\
+10 \text { ppb Se(VI) }\end{array}$ & $<0.01$ & 0.756 & 0.624 & $(1.71)$ \\
\hline $\begin{array}{c}\text { C. vulgaris } \\
+25 \text { ppb Se(VI) }\end{array}$ & 1.10 & 18.9 & 0.627 & $(21.0)$ \\
\hline $\begin{array}{c}\text { Porcupine River: } \\
\text { Upstream of Bloom* }\end{array}$ & 1.65 & 1.16 & $<0.01$ & $\begin{array}{c}(2.00 \\
(\mathbf{p p b})\end{array}$ \\
\hline $\begin{array}{c}\text { Porcupine River: } \\
\text { Algal Bloom Site }\end{array}$ & 1.10 & 0.711 & $<0.01$ & $\begin{array}{c}3.05 \\
(1.86)\end{array}$ \\
\hline $\begin{array}{c}\text { Porcupine River: } \\
\text { Downstream of Bloom }\end{array}$ & 1.10 & 0.609 & $<0.01$ & $\begin{array}{c}2.76 \\
(1.79)\end{array}$ \\
\hline
\end{tabular}

* Upstream of the major bloom; some algae was still present here during July 2011 sampling 


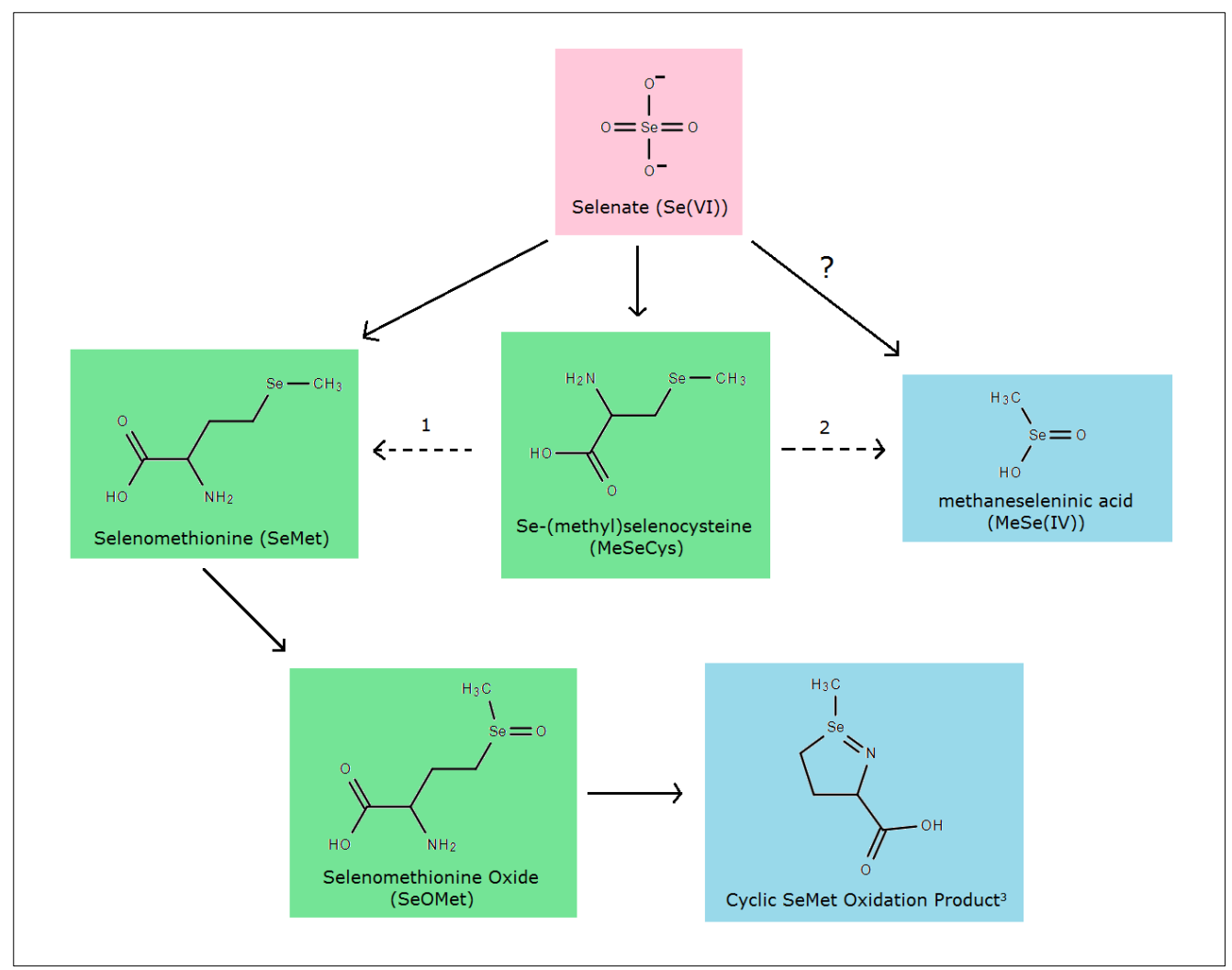

Figure S-1: Rough schematic of the biological formation of the observed organic Se metabolites produced by algae and bacteria exposed to inorganic selenium, as selenate. Pink: starting species, green: metabolites with identity confirmed by ES-MS/MS, blue: metabolites identified by coelution in AEC-ICP-DRC-MS. Dotted arrows: transformations that have been observed in the literature (details in text). 


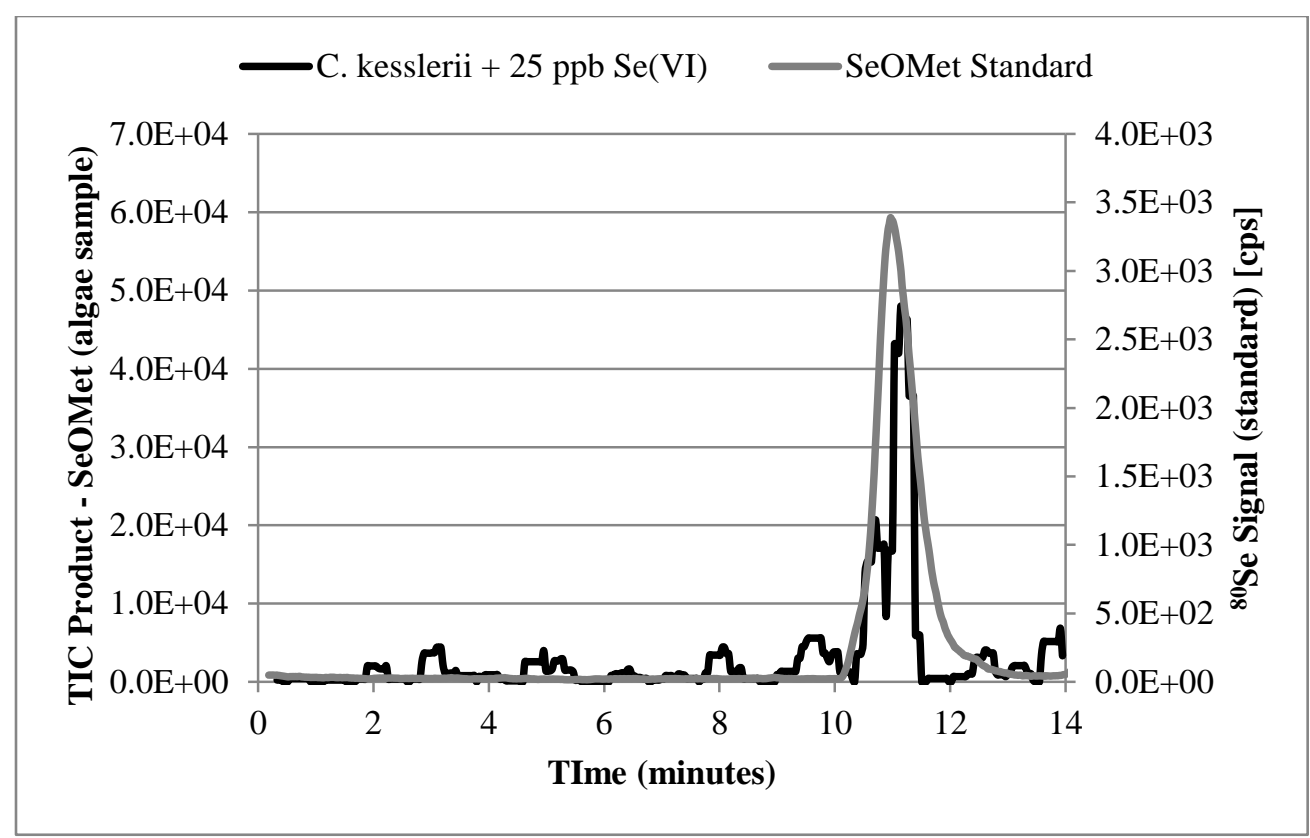

Figure S-2: AEC-ES-MS/MS chromatogram of the medium of a culture of Chlorella kesslerii grown in the presence of $25 \mathrm{ppb} \mathrm{Se}(\mathrm{VI})$. The product of four isotopic transitions $\left({ }^{77} \mathrm{Se},{ }^{78} \mathrm{Se}\right.$, ${ }^{80} \mathrm{Se}$, and ${ }^{82} \mathrm{Se}$ ) for the fragmentation $\mathrm{SeOMet}>\mathrm{SeCH}_{3} \mathrm{O}^{-}$is shown. Overlaid is the ${ }^{80} \mathrm{Se}$ signal for the AEC-ICP-DRC-MS analysis of a (freshly prepared) SeOMet standard to demonstrate coelution.

\section{References:}

(1) Moreno, F.; García-Barrera, T.; Gómez-Jacinto, V.; Gómez-Ariza, J.L.; Garbayo-Nores, I.; Vílchez-Lobato, C. Antagonistic interaction of selenomethionine enantiomers on methylmercury toxicity in the microalgae Chlorella sorokiniana. Metallomics. 2014, 6, 347-355.

(2) Block, E.; Birringer, M.; Jiang, W.; Nakahodo, T.; Thompson, H.J.; Toscano, P.J.; Uzar, H.; Zhang, X.; Zhu, Z. Allium Chemistry: Synthesis, Natural Occurrence, Biological Activity, and Chemistry of SeAlk(en)ylselenocysteines and Their $\gamma$-Glutamyl Derivatives and Oxidation Products. J. Agric. Food Chem. 2001, 49, 458-470.

(3) LeBlanc, K. L.; Ruzicka, J.; Wallschläger, D. Identification of Trace Levels of Selenomethionine and Related Organic Selenium Species in High Ionic Strength Waters. Anal. Bioanal. Chem. 2016, 408, 1033-1042. 